\title{
Determination of in-vitro Equivalence of Paracetamol Tablets
}

\author{
Athri D. Rathnayake ${ }^{1}$, Uthpali Mannapperuma ${ }^{2}$, Dhanusha Thambawita ${ }^{2}$, \\ Kamal P. B. Herath ${ }^{3}$, Priyadarshani Galappatthy ${ }^{2}$, Ravindra L. Jayakody ${ }^{2}$ \\ ${ }^{1}$ Department of Chemistry, University of Colombo, Sri Lanka \\ ${ }^{2}$ Department of Pharmacology, University of Colombo, Sri Lanka \\ ${ }^{3}$ M. S. J. Industries (Ceylon) (Private) Ltd, Sri Lanka
}

\begin{abstract}
Bioequivalence studies are the usually accepted method to determine the therapeutic equivalence of two drug products. Because in-vivo bioequivalence studies are time consuming and expensive to conduct, major regulatory authorities have introduced biowaivers for some selected medicines belonging to BCS class 1 and III drugs. Comparative dissolution tests are used in biowaiver procedure to waiver the bioequivalence requirement. We performed this study to see whether two brands of paracetamol tablets are bioequivalent using the in-vitro methodology. In the first stage of this research study, British Pharmacopeia 2012 quality tests were performed on the two selected paracetamol tablet products to determine whether they are pharmaceutically equivalent. In the second stage in-vitro equivalence of the two products was determined using the biowaiver testing procedure given by the World Health Organization. Dissolution profiles were generated at $\mathrm{pH}$ values, 1.2, 4.5 and 6.8. Results were compared through two model independent methods, difference factor $\left(f_{1}\right)$ and similarity factor $\left(f_{2}\right)$. The two paracetamol tablet products tested, complied with all the quality requirements of the British Pharmacopeia 2012. For the two products, the difference factor $\left(f_{1}\right)$ was below the 15 and similarity factor $\left(f_{2}\right)$ was above the 50 in all dissolution test conditions. These results confirm that the two products are pharmaceutically equivalent. The test product is also bioequivalent to the reference product in-vitro, and therefore they can be interchangeable during clinical use. This study shows that in-vivo bioequivalence testing can be waived using the in-vitro method, for some pharmaceutical products such as paracetamol tablets.
\end{abstract}

KEYWORDS: Paracetamol tablets, Biowaivers, Dissolution profiles 


\section{INTRODUCTION}

Paracetamol is an over the counter medication used widely as an analgesic agent for symptomatic management of mild to moderate pain. Also, it has excellent antipyretic properties and is used to reduce the body temperature in patients with fever (Kalantzi et al., 2006; Ellis et al., 2002). In Sri Lanka, as well as in other countries many brands and generics of paracetamol $(500 \mathrm{mg})$ tablets are available. These are formulated to be pharmaceutically equivalent to each other. Pharmaceutically equivalent drug products contain same molar amount of the same active pharmaceutical ingredient in the same dosage form if they meet comparable standards and administered by the same route. Pharmaceutical equivalence does not necessarily imply similarity of therapeutic effect. Therefore, there are concerns when it comes to substituting one brand of a pharmaceutically equivalent drug product to another in clinical practice (WHO, 2006; USP, 2012).

Pharmaceutically equivalent drug products should be bioequivalent (or therapeutically equivalent) to each other to be given interchangeably during the clinical practice. Two drug products are bioequivalent if they are pharmaceutically equivalent and their effects can be expected to be essentially the same after administration of the same molar dose under the same conditions. Bioequivalence (BE) testing is a comparative test, which uses specified criteria for comparison and have predetermined $\mathrm{BE}$ limits for such criteria (HHS/FDA, 2003; WHO, 2006a).

There are several in-vivo and in-vitro approaches to determine the equivalence of two pharmaceutically equivalent drug products.
These approaches include pharmacokinetic studies, pharmacodynamic studies, comparative clinical trial studies and in-vitro dissolution studies (HHS/FDA, 2003; WHO, 2006) Because in-vivo BE studies are time consuming and expensive to conduct, major regulatory authorities such as United States Food and Drug Administration (US-FDA) and World Health Organization (WHO) have introduced biowaivers. The biowaiver approach, waives invivo $\mathrm{BE}$ studies by the means of comparative in-vitro dissolution test and it's based on the Biopharmaceutical Classification System (BCS). There are only several pharmaceutical formulations which are currently being considered for biowaivers. According to the WHO, paracetamol is a BCS class I active pharmaceutical ingredient (highly soluble and highly permeable) thus making it eligible to be considered for biowaivers (HHS/FDA, 2003; WHO, 2006).

In biowaiver studies, comparison of dissolution profiles is done for two pharmaceutically equivalent products under identical conditions. In order to compare the dissolution profiles, similarity factor $\left(\mathrm{f}_{2}\right)$ and difference factor $\left(f_{1}\right)$ are used. The $f_{1}$ calculates the relative error based on the percent difference between the two dissolution profiles.

$$
\left.\mathrm{f}_{1}=\left\{\left[\sum_{\mathrm{t}=1}^{\mathrm{n}}\left|\mathrm{R}_{\mathrm{t}}-\mathrm{T}_{\mathrm{t}}\right|\right] / \sum_{\mathrm{t}=1}^{\mathrm{n}} \mathrm{R}_{\mathrm{t}}\right]\right\} \cdot 100 .
$$

The $f_{2}$ calculates the percent similarity between the two dissolution profiles.

$$
\mathrm{f}_{2}=50 . \log \left\{\left[1+\left(\frac{1}{\mathrm{n}}\right) \sum_{\mathrm{t}=1}^{\mathrm{n}}\left(\mathrm{R}_{\mathrm{t}}-\mathrm{T}_{\mathrm{t}}\right)^{2}\right]^{-0.5} .100\right\}
$$

In above equations, $n$ is the number of sampling time points used to draw a drug dissolution profile, $R_{t}$ is dissolution value of the 
reference batch at time $t$ and $T_{t}$ is dissolution value of the test batch at time $t$.

Generally a $\mathrm{f}_{1}$ value up to $15(0-15)$ and a $\mathrm{f}_{2}$ value greater than 50 (50-100) indicates the equivalence of the two dissolution profiles

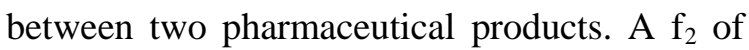
50 represents an average $10 \%$ difference of drug release at all sampling time points, while a $\mathrm{f}_{2}$ of 100 represents zero average difference of drug release at all sampling time points (HHS/FDA, 1997).

This study was carried out to investigate the in-vitro equivalence of selected two paracetamol $500 \mathrm{mg}$ tablet products, taking the market leader product as the reference product and the brand currently utilized in the public sector as the test product. In order to declare the pharmaceutical equivalency of these two paracetamol tablet products quality testing methods of British Pharmacopeia 2012 (BP 2012) paracetamol tablet monograph were used.

\section{MATERIALS AND METHODS}

\subsection{Materials}

Reference paracetamol tablets (Panadol) was obtained as a donation for the purpose of the research study from GlaxoSmithKline, Sri Lanka. Test paracetamol tablets (SPMC Paracetamol) were obtained from the Lady Ridgeway Hospital for Children via request from the Medical Supplies Division, Ministry of Health, Sri Lanka. Paracetamol working standard, 4-aminophenol, and tetrabutylammonium hydroxide were obtained as a donation from Astron Limited, Sri Lanka for the paracetamol related substance test. All the chemicals used for the research study were analytical reagent grade. For the related substance test HPLC graded chemicals were used.

\subsection{Quality Testing for Two Products of Paracetamol $500 \mathrm{mg}$ Tablets According to the BP 2012}

Uniformity of mass: Uniformity of mass test was performed on CAS CAY 120 electronic balance. Three trials were conducted for the 2 products separately (BP, 2012).

Assay: Analysis of paracetamol was done according to the BP 2012 Paracetamol tablets monograph assay using CAS CAY 120 electronic balance and JASCO V-560 UV/VIS spectrophotometer. Three trials were performed for each product (BP, 2012).

Friability of paracetamol tablets: The friability of randomly selected eleven tablets were investigated using EP 420A-FR Electronic balance and ERWEKA Friability Tester. Three trials were performed for each product (BP, 2012).

\section{Resistance to crushing of paracetamol} tablets: Hardness of randomly selected 10 tablets was investigated using ERWEKA hardness tester. Three trials were performed for each tablet product [8].

Dissolution: A volume of $900 \mathrm{ml}( \pm 1 \%)$ of phosphate buffer pH 5.8 (Prepared according to the BP 2012) was placed in the each vessel of the PHARMA TEST dissolution apparatus. Dissolution medium was equilibrated to $37 \pm$ $0.5{ }^{0} \mathrm{C}$. Six tablets were randomly selected for the dissolution test. Prior to commencement of the test, care was taken to exclude air bubbles from the surface of the tablets. Paddles were rotated at 50 revolutions per minute, for 45 
minutes. Sample medium was collected at 5, $10,15,20,30,45$ minutes from all 6 vessels using the auto sampler system. One milliliter of the collected samples was diluted to $10.00 \mathrm{ml}$ with $0.1 \mathrm{M}$ sodium hydroxide. One milliliter of the resulting solutions were diluted up to 10.00 $\mathrm{ml}$ with $0.1 \mathrm{M}$ sodium hydroxide. This dilution procedure was carried out for all 36 samples and absorbance was measured using VARIAN CARY-50 Bio UV/VIS spectrophotometer at $257 \mathrm{~nm}$ using $0.1 \mathrm{M}$ sodium hydroxide in the reference cell. Percentage release of the drug from paracetamol tablets was determined. Dissolution profile was plotted for each tablets. The same procedure was followed for the two tablet products separately.

Related substance test: Analysis of 4aminophenol content in the paracetamol tablets was done using high performance liquid chromatography (SHIMADZU HPLC machine and $\mathrm{C}_{8}$ stainless steel column with dimension of $25 \mathrm{~cm} \mathrm{X} 4.6 \mathrm{~mm}$ ) according to the BP 2012 paracetamol tablets related substance test (BP, 2012).

Following solutions were prepared immediately before the test was started and covered with aluminum foil in order to protect those from light.

Solution - 1: Powdered tablet from each product containing $0.2 \mathrm{~g}$ of paracetamol was dispersed in $8.00 \mathrm{ml}$ of the mobile phase using sonicator. Sufficient volume of mobile phase was added to produce $10.00 \mathrm{ml}$ of the solution. Resulting solution was mixed well and filtered. Separate solutions have been made for the two paracetamol products using above procedure.

Solution - 2: Volume of $1.00 \mathrm{ml}$ of solution 1 has been diluted to $20.00 \mathrm{ml}$ with mobile phase.
Volume of $1.00 \mathrm{ml}$ of this solution has been diluted up to $20.00 \mathrm{ml}$ with mobile phase.

Solution - 3: Volume of $100.00 \mathrm{ml}$ containing $0.002 \% \mathrm{w} / \mathrm{v}$ 4-aminophenol in the mobile phase and volume of $100.00 \mathrm{ml}$ containing $0.002 \% \mathrm{w} / \mathrm{v}$ paracetamol reference standard in the mobile phase were mixed together to produce $200 \mathrm{ml}$ of the solution.

Preparation of mobile phase and adjustment of mobile phase parameters were done as follows.

Volume of $1000.0 \mathrm{ml}$ of HPLC graded methanol containing $4.60 \mathrm{~g}$ of a $40 \% \mathrm{v} / \mathrm{v}$ solution of tetrabutylammonium hydroxide was made and filtered using pore size of 0.45 micrometer cellulose acetate filter paper. Volume of $1000.0 \mathrm{ml}$ of $0.05 \mathrm{M}$ disodium hydrogen orthophosphate (analytical reagent grade of commerce) and $1000.0 \mathrm{ml}$ of $0.05 \mathrm{M}$ sodium dihydrogen orthophosphate (analytical reagent grade of commerce) were mixed together and filtered using pore size of 0.45 micrometer cellulose acetate filter paper. In order to make the $1000 \mathrm{ml}$ of mobile phase, 250 $\mathrm{ml}$ of methanol containing $1.15 \mathrm{~g}$ of $40 \% \mathrm{v} / \mathrm{v}$ solution of tetrabutylammonium hydroxide were mixed with $750 \mathrm{ml}$ of the mixture of $0.05 \mathrm{M}$ sodium dihydrogen orthophosphate and disodium hydrogen orthophosphate. Mobile phase flow rate was adjusted to $1 \mathrm{ml}$ per minute at a temperature of $35{ }^{\circ} \mathrm{C}$. Volume ratio has been adjusted as 1 volume of methanol contains $40 \% \mathrm{v} / \mathrm{v}$ solution of tetrabutylammonium hydroxide to 3 volume of phosphate buffer. Detection wavelength was adjusted to $245 \mathrm{~nm}$.

Injection of prepared solutions and results interpretation of obtained chromatograms were done according to BP 2012. 


\subsection{Determination of in-vitro Equivalence of Paracetamol $500 \mathrm{mg}$ Tablets}

For each product at each $\mathrm{pH}(\mathrm{pH} 1.2$ $\mathrm{HCl}, \quad \mathrm{pH} 4.5$ acetate buffer and $\mathrm{pH} 6.8$ phosphate buffer), a volume of $900 \mathrm{ml}( \pm 1 \%)$ of the dissolution media was placed in each and every vessel of the PHARMA TEST dissolution apparatus. Dissolution medium was equilibrated to $37 \pm 0.5{ }^{\circ} \mathrm{C}$. Twelve tablets were randomly selected for the dissolution test. Prior to the commencement of the test care was taken to exclude air bubbles from the surface of the tablets. Paddles were rotated at 75 revolutions per minute, for 45 minutes. Samples of dissolution medium were collected at 5, 10, 15, 20,30, 45 minutes from all 6 vessels using auto sampler system. The dilution procedure described in the BP 2012 was carried out to dilute all the 72 samples and their absorbance was measured using VARIAN CARY-50 Bio UV/VIS spectrophotometer according to the procedure describe under the section 2.2 dissolution test. Average percentage release of the drug from paracetamol tablets in each time point was determined in order to apply those values for the calculation of $f_{2}$ and $f_{1}$.

\section{RESULTS AND DISCUSSION}

\subsection{Quality Testing for Two Products of Paracetamol $500 \mathrm{mg}$ Tablets According to the BP 2012}

Uniformity of mass: Results of uniformity of mass test for both products are illustrated in Table 1. According to the BP uniformity of mass test, for tablets weighing more than 250 $\mathrm{mg}$, permissible percentage deviation of the mass is $5 \%$. In order to comply for the requirement of uniformity of mass test, more than 2 of the individual masses should not deviate from the average mass by more than the percentage deviation, and none should deviate more than twice the percentage (BP, 2012). Thus both products complied with the requirements for BP uniformity of mass test.

Assay: Results achieved from analysis of active ingredient (paracetamol) in both products are given in Table 1. As per BP 2012 specifications, the content should not be less than $95 \%$ and not more than $105 \%$ of labeled amount of the tablets (BP, 2012). Results indicate the reference product assay value is in the acceptable limits. Despite the second assay trial failing by $0.6 \%$, the average content of the labeled amount of the test product is in the accepted BP range.

Friability of paracetamol tablets: Friability test is to ensure that tablets possess a suitable mechanical strength to avoid abrasion, crumbling or breaking on handling or subsequent processing. Results achieved from the friability test in both products are given in Table 1. A BP 2012 specification for friability is a maximum loss of mass not greater than 1.0 $\%$ (BP, 2012). Thus both products comply with the specifications of the $\mathrm{BP}$

Resistance to crushing of tablets: The hardness or crushing strength of tablets assesses the ability of tablets to withstand handling without fracturing or chipping. The results were interpreted as average hardness of 10 tablets, minimum hardness value, and maximum hardness value according to the BP (BP, 2012). Results achieved from hardness test for both products are given in Table 1.

Dissolution: Dissolution profiles for the two products are shown in Figure 1 and Figure 2. According to the harmonized dissolution 
criteria, no unit must release the drug product less than $80 \%$ of the labeled amount in 45 minutes. Hence both products comply with the BP dissolution test.

Related Substance Test: The major impurity of paracetamol raw material is 4-aminophenol. The quantity of 4-aminophenol present in a paracetamol tablet must be strictly controlled as 4-aminophenol has nephrotoxic and teratogenic effects (Ca linescu et al., 2012). Because of the resolution factor between the two principal peaks of the chromatogram obtained with the reference solution is 5.587 which is greater than 4.0, the HPLC test was accepted as a valid test according to BP 2012.

The chromatogram obtained with solution - 1 for reference product, the area of the peak correspond to 4-aminophenol is not greater than area of corresponding peak of 4aminophenol in the chromatogram obtained with standard solution - 3. The chromatogram obtained with solution - 1 for test product, the area of the peak corresponds to 4-aminophenol is not greater than area of corresponding peak of 4-aminophenol in the chromatogram obtained with standard solution - 3. No other impurity (peaks correspond to impurities in solution - 1 of both products) is greater than the area of the principal peak obtained with solution - 2 of both products. Thus the levels of 4-aminophenol in both the paracetamol tablet products were below the level specified in the BP.

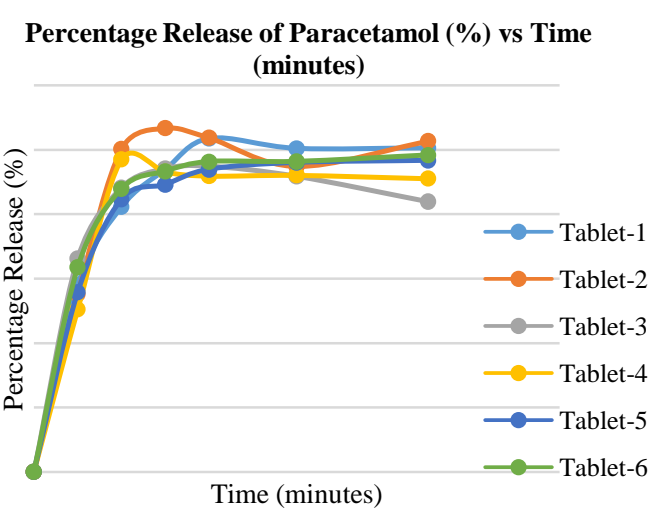

Figure 1. Dissolution profiles of six tablets of the reference product at $\mathrm{pH} 5.8$ phosphate buffer

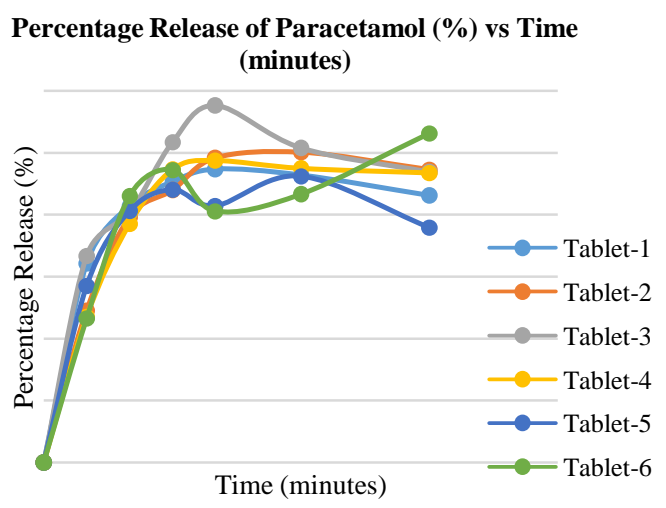

Figure 2. Dissolution profiles of six tablets of the test product at $\mathrm{pH} 5.8$ phosphate buffer 
TABLE 1. Results of the Uniformity of Mass, Assay, Friability Test and Hardness Test (Test for Resistant to Crushing of Tablets).

\begin{tabular}{|c|c|c|c|c|c|c|}
\hline \multirow[t]{2}{*}{ Test } & \multicolumn{3}{|c|}{ Reference Product } & \multicolumn{3}{|c|}{ Test Product } \\
\hline & $\begin{array}{l}\text { Trial } \\
1\end{array}$ & Trial 2 & Trial 3 & Trial 1 & Trial 2 & $\begin{array}{l}\text { Trial } \\
3\end{array}$ \\
\hline \multicolumn{7}{|l|}{$\begin{array}{l}\text { Uniformity } \\
\text { of mass }\end{array}$} \\
\hline $\begin{array}{l}\text { Accepted } \\
\text { mass } \\
\text { deviation } \\
\text { range }(\mathrm{g})\end{array}$ & $\begin{array}{l}0.564 \\
7- \\
0.624 \\
1\end{array}$ & $\begin{array}{l}0.5612 \\
- \\
0.6203\end{array}$ & $\begin{array}{l}0.5637 \\
- \\
0.6230\end{array}$ & $\begin{array}{l}0.5435 \\
- \\
0.6007\end{array}$ & $\begin{array}{l}0.5969 \\
- \\
0.5401\end{array}$ & $\begin{array}{l}0.5436 \\
- \\
0.6008\end{array}$ \\
\hline $\begin{array}{l}\text { Number of } \\
\text { tablets } \\
\text { outside the } \\
\text { deviation } \\
\text { range }\end{array}$ & None & None & None & None & 2 & None \\
\hline \multicolumn{7}{|l|}{ Assay } \\
\hline $\begin{array}{l}\text { Content of } \\
\text { paracetamol } \\
\text { as a } \\
\text { percentage } \\
\text { of labeled } \\
\text { amount (\%) }\end{array}$ & 103.7 & 99.9 & 101.1 & 97.2 & 94.4 & 96.6 \\
\hline \multicolumn{7}{|l|}{$\begin{array}{l}\text { Friability } \\
\text { test }\end{array}$} \\
\hline $\begin{array}{l}\text { Percentage } \\
\text { loss of mass } \\
(\%)\end{array}$ & $\begin{array}{l}0.453 \\
9\end{array}$ & 0.0736 & 0.0369 & 0.1964 & 0.0862 & 0.5255 \\
\hline \multicolumn{7}{|l|}{$\begin{array}{l}\text { Hardness } \\
\text { test }\end{array}$} \\
\hline $\begin{array}{l}\text { Average } \\
\text { hardness } \\
(\mathrm{N})\end{array}$ & 151 & 148 & 146 & 130 & 135 & 131 \\
\hline $\begin{array}{l}\text { Minimum } \\
\text { hardness } \\
(\mathrm{N})\end{array}$ & 136 & 136 & 136 & 099 & 099 & 097 \\
\hline $\begin{array}{l}\text { Maximum } \\
\text { hardness } \\
\text { (N) }\end{array}$ & 156 & 156 & 154 & 148 & 148 & 148 \\
\hline
\end{tabular}

\subsection{Determination of in-vitro Equivalence of Paracetamol $500 \mathrm{mg}$ Tablets}

Dissolution tests (Table 2) were carried out in order to determine the in-vitro equivalence of two paracetamol tablet products adopting the biowaiver testing procedure proposed by the WHO. Dissolution profile comparison (Figure 3, Figure 4 and Figure 5) of the two paracetamol tablets (in all the three dissolution media) was done according to the recommendations given by US-FDA. Calculated values of $f_{1}$ and $f_{2}$ are given in Table 2.

Because the $\mathrm{f}_{2}$ for all three dissolution media is within the range of 50-100 and the $f_{1}$ for all three dissolution media is within the range of 0-15 there is a similarity of dissolution profile of both products in all the three dissolution media.

\section{Average percentage release of Paracetamol (\%) vs Time (minutes)}

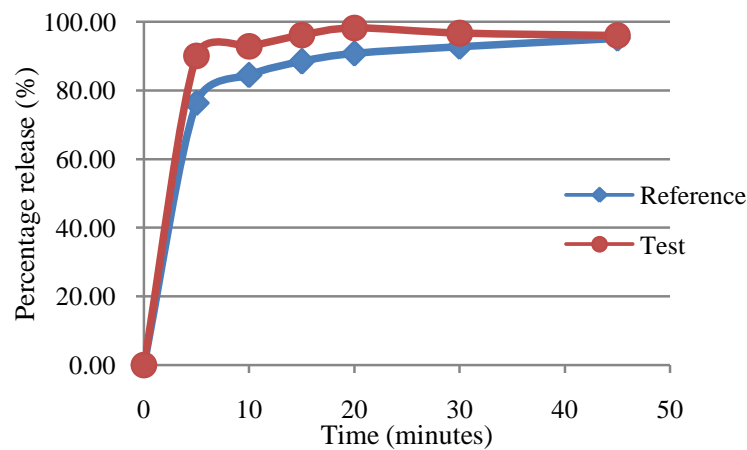

Figure 3. Dissolution profiles of paracetamol tablets in $\mathrm{pH} 1.2 \mathrm{HCl}$ media

Average percentage release of Paracetamol (\%) vs Time (minutes)

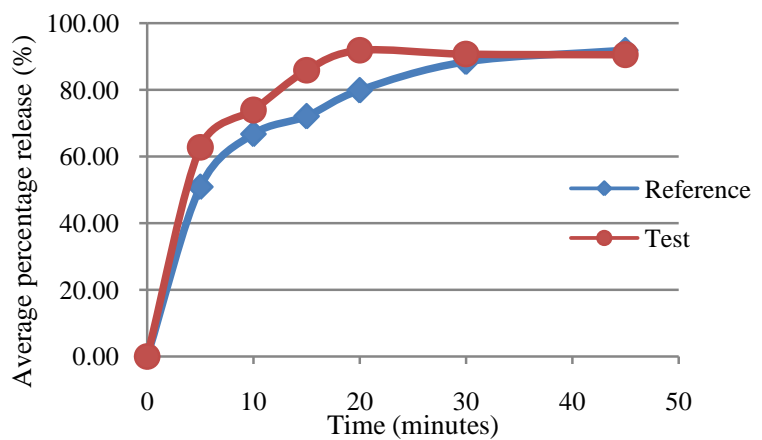

Figure 4. Dissolution profiles of paracetamol tablets in $\mathrm{pH} 4.5$ acetate buffer 


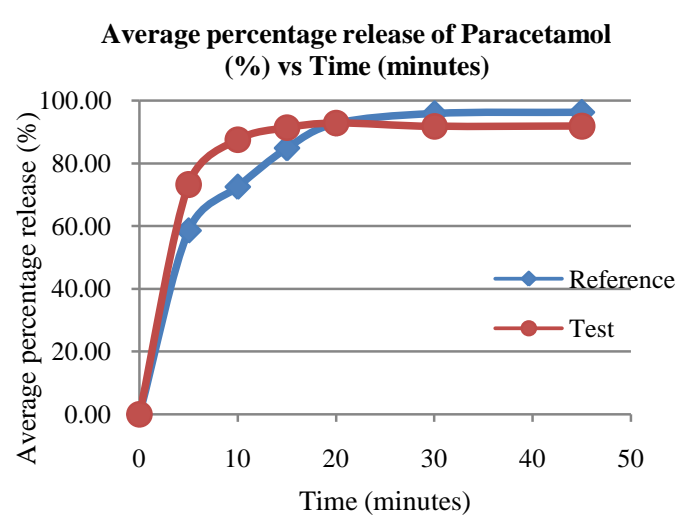

Figure 5. Dissolution profiles of paracetamol tablets in $\mathrm{pH} 6.8$ phosphate buffer

TABLE 2. Dissolution Tests Carried Out In Order to Determine the in-vitro Equivalence of Paracetamol Tablets and Calculated Similarity Factor $\left(f_{2}\right)$ and Difference Factor $\left(f_{1}\right)$.

\begin{tabular}{|c|c|c|c|c|c|}
\hline Test & Products & $\begin{array}{l}\text { Number } \\
\text { of } \\
\text { tablets }\end{array}$ & $\begin{array}{l}\text { Dissolution } \\
\text { media }\end{array}$ & $\mathbf{f}_{1}$ & $\mathbf{f}_{2}$ \\
\hline \multirow[t]{2}{*}{1} & Reference & 12 & $\begin{array}{lll}\mathrm{pH} & 1.2 & \mathrm{HCl} \\
\text { Solution } & \end{array}$ & \multirow[t]{2}{*}{7.971} & \multirow[t]{2}{*}{56.18} \\
\hline & Test & 12 & $\begin{array}{lll}\mathrm{pH} \quad 1.2 & \mathrm{HCl} \\
\text { Solution } & \end{array}$ & & \\
\hline \multirow[t]{2}{*}{2} & Reference & 12 & $\begin{array}{l}\mathrm{pH} 4.5 \text { Acetate } \\
\text { Buffer }\end{array}$ & \multirow[t]{2}{*}{10.18} & \multirow[t]{2}{*}{51.17} \\
\hline & Test & 12 & $\begin{array}{l}\mathrm{pH} 4.5 \text { Acetate } \\
\text { Buffer }\end{array}$ & & \\
\hline \multirow[t]{2}{*}{3} & Reference & 12 & $\begin{array}{ll}\text { pH } & 6.8 \\
\text { Phosphate } & \\
\text { Buffer } & \\
\end{array}$ & \multirow[t]{2}{*}{5.554} & \multirow[t]{2}{*}{51.44} \\
\hline & Test & 12 & $\begin{array}{ll}\mathrm{pH} & 6.8 \\
\text { Phosphate } & \\
\text { Buffer } & \\
\end{array}$ & & \\
\hline
\end{tabular}

\section{CONCLUSION}

Reference paracetamol tablets comply with all the BP 2012 quality specifications such as the uniformity of mass, assay, dissolution, related substances test, hardness test, and friability test. Test paracetamol tablets also comply with all the BP quality specifications. It can be concluded that the test product is pharmaceutically equivalent to the reference product.

$$
\text { In-vitro equivalence test was carried }
$$
out as the second stage of the research study. Similarity factor was calculated for all the three dissolution media. Similarity factor is 56.18 for the $\mathrm{pH} 1.2 \mathrm{HCl}$ solution, 51.17 for the $\mathrm{pH} 4.5$ acetate buffer and 51.44 for the $\mathrm{pH} 6.8$ phosphate buffer. Since the similarity factor is within the accepted range $(50$ - 100) for profile similarity in all three media, the test paracetamol tablet brand demonstrates equivalent dissolution to the reference paracetamol tablet brand in-vitro. Thus it can be concluded that the two products can be substituted with each other during the clinical practice. Results of this study indicates the possibility of post marketing evaluation of pharmaceutically equivalent products in-vitro as a substitute for in-vivo bioequivalence testing.

\section{REFERENCES}

ELLIS, F. (2002). Paracetamol - a curriculum resource. Royal Society of Chemistry.

\section{BRITISH PHARMACOPOEIA COMMISSION} (2012). British Pharmacopeia. Stationary office, London.

CALINESCU, O., BADEA, IA., VLA $־ E S C U$, L., MELTZER, V AND PINCU, E. (2012). HPLC Separation of Ac-etaminophen and its Impurities Using a Mixed-mode Reversed-Phase/Cation Exchange Stationary Phase. Journal of Chromatographic Science. 50, 335-342.

HHS/FDA GUIDANCE FOR INDUSTRY (2003). Bioavailability and Bioequivalence studies for Orally Administered Drug products-General Considerations. U.S. Department of Health and Human Services 
Food and Drug Administration, Rockville, MD.

HHS/FDA GUIDANCE FOR INDUSTRY (1997). Dissolution Testing of Immediate Release Solid Oral Dosage Forms. U.S. Department of Health and Human Service Food and Drug Administration, Rockville, MD.

KALANTZI, L., REPPAS, C., DRESSMAN, JB., AMIDON, GL., JUNGINGER, HE., MIDHA, KK., SHAH, VP., STAVCHANSKY, SA AND BARENDS, DM. (2006). Biowaiver monographs for immediate release solid oral dosage forms: Acetaminophen (paracetamol). Journal of Pharmaceutical Science. 95, 4-14.

WHO EXPERT COMMITTEE ON SPECIFICATIONS

FOR

PHARMACEUTICAL PREPARATIONS (2006). Annex 7: Multisource (generic) pharmaceutical products: guidelines on registration requirements to establish interchangeability. WHO technical report series, No. 937. World Health Organization, Geneva.

WHO EXPERT COMMITTEE ON SPECIFICATIONS FOR PHARMACEUTICAL PREPARATIONS (2006). Annex 8: Proposal to waive in-vivo bioequivalence requirements for WHO Model List of Essential Medicine immediate-release, solid oral dosage forms. WHO technical report series, No. 937. World Health Organization Geneva.

UNITED STATES PHARMACOPEIA CONVENTION (2012). United States Pharmacopeia. Rockville, MD.

\section{ACKNOWLEDGMENTS}

We would like to express our sincere gratitude to Mrs. Menike, Mrs. Chithra, and Mrs. Nisha and all the Pharmaceutical Chemistry Laboratory staff of the Department of Pharmacy and Department of Pharmacology, University of Colombo, Sri Lanka for the technical guidance.

We would also like to thank Professor Sujatha Heage for giving us the opportunity to use the Sri Lanka Pharmaceutical Laboratory, Department of Chemistry, University of Colombo, Sri Lanka for this research study. We would offer our kind gratitude to Mr. Paasha and Ms. Sudheera (Laboratory staff of Sri Lanka Pharmaceutical Laboratory) for the technical guidance. I would also like thank to all the laboratory staff of Center for Analytical Research and Development, Department of Chemistry, University of Colombo, Sri lanka.

We would like to thank Mrs. Hemamali Tibbotumunuwa (Regulatory Affairs Manager, GlaxoSmithKline), Dr. Rathnasiri A. Hewage (Director, Lady Ridgeway Hospital for Children) and Dr. Parakrama Herath (Former general manager of Quality operations, Regulatory and Research, Astron Limited, Sri Lanka) for donating the samples of paracetamol tablets and chemicals for the research study. 